\title{
REGIONAL VARIATION IN THE CURRENT FLOW ACROSS AN INSECT BLOOD-BRAIN BARRIER
}

\author{
By P. J. S. SMITH ${ }^{1,2, *}$ AND A. SHIPLEY ${ }^{1}$ \\ ${ }^{1}$ The National Vibrating Probe Facility, Marine Biological Laboratory, \\ Woods Hole, Massachusetts, USA and ${ }^{2}$ AFRC Unit of Insect Neurophysiology \\ and Pharmacology, Department of Zoology, Downing Street, Cambridge, UK
}

Accepted 22 June 1990

\begin{abstract}
Summary
One notable characteristic of the insect and vertebrate central nervous system is the presence of a clearly defined blood-brain barrier. In the insect this barrier is made up of the perineurial glial cells, and shows a heterogeneity in structure and possibly function between the connectives and ganglia. In this paper we have used a two-dimensional vibrating probe to investigate the net flow of electrical current across the barrier at various locations in the abdominal nervous system. The results show clear differences between different areas. There is a strong and consistent outward current flow $\left(3.16 \mu \mathrm{A} \mathrm{cm}^{-2}\right)$ perpendicular to the ganglion surface over the equatorial plane. Current returns through the peripheral nerves and the connectives. A detailed study of the latter shows that the net inward flow is principally over the initial section, immediately adjacent to the ganglia $\left(2.11 \mu \mathrm{A} \mathrm{cm}^{-2}\right)$. The different current polarities can be correlated with structural differences in the underlying glial cells.
\end{abstract}

\section{Introduction}

Insects possess a well-developed blood-brain barrier, a feature they share with the higher vertebrates (see Abbott and Treherne, 1977). This barrier is, in part, responsible for restricting any fluctuations in the ionic composition of the brain microenvironment and for keeping these within tolerable limits. However, whereas the vertebrate central nervous system (CNS) can rely on a comparatively stable blood ion composition and a large internal fluid reservoir in the form of the cerebral spinal fluid, some insects must live with both dramatic fluctuations in blood ion levels and a highly restricted extracellular space (Treherne, 1985). The insect neuroglia cope with these problems, playing a critical role in regulating the distribution of ions, particularly potassium, both within the nervous system and between the brain and the external environment.

* Present address: AFRC Laboratory of Molecular Signalling, Department of Zoology, Downing Street, Cambridge, UK.

Key words: blood-brain barrier, current flow, vibrating probe, insect, Periplaneta americana. 
The superficial glial layer, the perineurium of the insect central nervous system, forms the blood-brain barrier (Treherne, 1985). It appears to be heterogeneous in nature, with clear structural differences existing between the perineurial cells of the ganglia and those of the connectives (Hess, 1958; Maddrell and Treherne, 1967). Electrically these areas also differ in the characteristics of the transperineurial potential (Schofield, 1990). The underlying cause of these regional differences is probably related to their physiological role. The connectives contain only the axonal portion of the neurones whereas, in the ganglion, en passant axons and dendritic arborizations occupy the core, with neuronal cell bodies located round the exterior (Weevers, 1985). These organisational differences might be expected to pose unique problems for the blood-brain barrier, particularly with regard to the spatial distribution of potassium ions.

In this study the net movement of charge across the ganglionic and connective perineurial layers in the cockroach CNS is measured. This is done using an externally located two-dimensional vibrating probe. The results correlate with ultrastructural differences between the areas under the probe recording sites.

\section{Materials and methods}

The insect used in this study was the American cockroach, Periplaneta americana (L.), fed and watered ad libitum.

The animals were decapitated and pinned ventral surface downwards on a Sylgard plate. The abdominal section of the central nervous system was dissected out, taking care to avoid damage that could have produced artefactual injury currents. Since preliminary experiments showed that cutting the tracheae close to the nervous system induced such currents, lengths of at least $1 \mathrm{~mm}$ were left undamaged where they arose from the fourth and fifth abdominal ganglia and the penultimate connective. Similarly, lengths of the median nerves were also left attached to the ganglia. The entire abdominal nervous system was removed and handled by its extremities. Such a dissection gave consistent patterns of current flow between preparations.

After dissection, the nerve cord was secured to the Sylgard base of an experimental chamber filled with cockroach Ringer (in mmol ${ }^{-1}$ : trehalose, 5; Hepes, $8.6 ; \mathrm{KOH}, 3 ; \mathrm{NaCl}, 157 ; \mathrm{CaCl}_{2}, 2 ; \mathrm{MgCl}_{2}, 2$ ). This solution has a $\mathrm{pH}$ of 7.2 , an osmolarity of 303 mosmoll $^{-1}$ and a resistivity of $88 \Omega$. Throughout, the experimental temperature was $24^{\circ} \mathrm{C}$. Under these conditions the current flowing across the barrier stabilised in $1 \mathrm{~h}$ and could be measured for at least $24 \mathrm{~h}$.

Extracellular currents were measured with a two-dimensional vibrating probe; a technique described in detail elsewhere (Jaffe and Nuccitelli, 1974; Jaffe, 1985; Scheffey, 1988). Briefly, wire probes, coated with platinum black (Scheffey, 1988) to a final tip diameter of between 8 and $12 \mu \mathrm{m}$, were positioned so that the closest point of vibration was within $5 \mu \mathrm{m}$ of the surface of the tissue. Probes such as thescan detect a voltage drop in the nanovolt range across calibrated excursions d. approximately twice the tip diameter. In media of known resistivity this can be 
converted to a current density. As the probe oscillates in two planes, in these experiments the $x$ and $y$ directions, the current has a directionality and can be plotted as a vector with polarities conforming to conventional current flow. Data collection and conversion to current densities and vectors were carried out by an automated data-acquisition system designed specifically for the two-dimensional probe and based on a DEC 11/23 microcomputer (Scheffey, 1988). Voltages were averaged over a $10 \mathrm{~s}$ period. Prior to each experiment the probes were calibrated in the experimental chamber using a $30 \mathrm{nA}$ current source. Throughout the experiments the reference stability was frequently checked by measuring the peak-topeak noise level at a distance of $200-300 \mu \mathrm{m}$ from the preparation. A significant change in the noise level could be subtracted from the measured voltage by correcting the reference value.

This study concentrated on the current field around the fourth abdominal ganglion, its median nerve and the penultimate connective joining the fourth ganglion with the fifth. Two probe rigs were used during these experiments, one equipped with an inverted microscope and the other with normal optics. In both cases current measurements were made around the equatorial plane of the ganglia or connective when viewed from either the dorsal or ventral surface. Both rigs examined the same areas of tissue and no difference was seen between the measurements made from either rig.

For ultrastructural observation tissues were fixed in $2.5 \%$ glutaraldehyde made up in $0.05 \mathrm{moll}^{-1}$ Sorensen's buffer plus $6 \%$ sucrose. A standard dehydration procedure was followed and the material embedded in Araldite. Sections were cut on a Reichert/Jung Ultracut ultramicrotome. They were examined and photographed using a Philips 420 electron microscope.

\section{Results \\ Current flow from ganglia}

Current flowed outwards along the equatorial plane of the fourth abdominal ganglion with a mean amplitude of $3.16 \pm 0.42 \mu \mathrm{A} \mathrm{cm}{ }^{-2}$ ( \pm S.E., Table 1 ), a value higher than could be accounted for by the peak-to-peak noise level during the same experiments $\left(0.88 \pm 0.45 \mu \mathrm{A} \mathrm{cm}^{-2}\right)$. In several preparations current measurements were made from the same points on the ganglionic surface. In these cases the data could be pooled and plotted relative to the surface (Fig. 1). Along the ganglion edge the amplitudes of these vectors were generally between 3 and $4 \mu \mathrm{A} \mathrm{cm}^{-2}$, rising perpendicular to the surface of the tissue. In all cases angles were measured relative to the long axis of the cord, such that an anteriorly directed current would have an angle of $180^{\circ}$ and a posteriorly directed current one of $0^{\circ}$. Cursory examination of the fifth ganglion in two preparations indicated that this also had an outwardly directed vector of a similar magnitude.

Electron microscopical examination of the cells beneath the probe positions in he equatorial plane revealed a uniform and characteristic cell type. These cells were distinctive in the high density of mitochondria present (Fig. 2). In many cases 
Table 1. Current amplitudes measured round the insect abdominal nerve cord

\begin{tabular}{lcc}
\hline Location & $\begin{array}{c}\text { Number of preparations } \\
\text { (of vectors) }\end{array}$ & $\begin{array}{c}\text { Amplitude } \\
\left(\mu \mathrm{A} \mathrm{cm}^{-2} \pm \mathrm{S} . \mathrm{E} .\right)\end{array}$ \\
\hline $\begin{array}{l}\text { Fourth ganglion } \\
1 \text { Equatorial plane }\end{array}$ & $15(82)$ & $\begin{array}{c}\text { Outward } \\
3.16 \pm 0.42\end{array}$ \\
Connective & & Inward \\
2 Within $300 \mu \mathrm{m}$ of the fourth ganglion & $9(24)$ & $2.11 \pm 0.41$ \\
3 Central, approx. $1.5 \mathrm{~mm}$ from the ganglia & $2(31)$ & $0.82 \pm 0.25$ \\
Peripheral nerve & & Inward \\
$4200 \mu \mathrm{m}$ distal to the fourth ganglion & $2(3)$ & $2.68 \pm 0.13$
\end{tabular}

Variation in the peak-to-peak noise levels, measured $200-300 \mu \mathrm{m}$ from the surface of the preparations, is shown in Fig. 1 for data values 1,2 and 3. Variation in the peak-to-peak noise levels relevant to data value 4 is given in Table 2 .

The vectors referred to in the second column represent the number of individual measurements of current flow through the blood-brain barrier.

these organelles appeared closely associated with additional membrane structures (Fig. 3) that had a superficial resemblance to smooth endoplasmic reticulum.

\section{Current flow from the penultimate connectives}

The pattern of current flow through the connective was less obvious than that from the ganglion. Between 100 and $300 \mu \mathrm{m}$ down the connective from the ganglion, current invariably flowed inwards with a mean amplitude of $2.11 \pm 0.41 \mu \mathrm{A} \mathrm{cm}^{-2}$ ( \pm S.E., Table 1 ). Where data were collected from the same point along the connective and could be pooled, a mean vector was plotted (Fig. 1). Here the amplitude was $2.5 \pm 0.45 \mu \mathrm{A} \mathrm{cm}^{-2}$ with a vector angle of $298^{\circ}$. As with the ganglion, the vector angle was almost perpendicular to the surface but with the opposite polarity. The peak-to-peak variation in the background noise given in Fig. 1 applied both to these data and to the values for the ganglion.

Further down the connective the pattern of current flow was less clear. In general the polarity appeared to be inward, but the angles were variable and the amplitudes less than those from the ganglionic region (Tables 1, 2). Also, it was not clear whether the current flow measured in this region exceeded the noise value. Table 2 compares the amplitudes and angles of current flow from the central region of two connectives with the peak-to-peak noise levels over the same time. No significant inward current can be claimed on the basis of these data.

The perineurial glial cells beneath the probe at both positions in the connective appeared identical. Here the blood-brain barrier was made up of attenuated and overlapping cell processes with sparsely distributed nuclei. As shown in Fig. 4 taken from tissue near the fourth ganglion, none of the cells carried the hig density of mitochondria and membrane structures seen in the ganglionic cells. 
$3 \mu \mathrm{A} \mathrm{cm}^{-2} / 150 \mu \mathrm{m}$

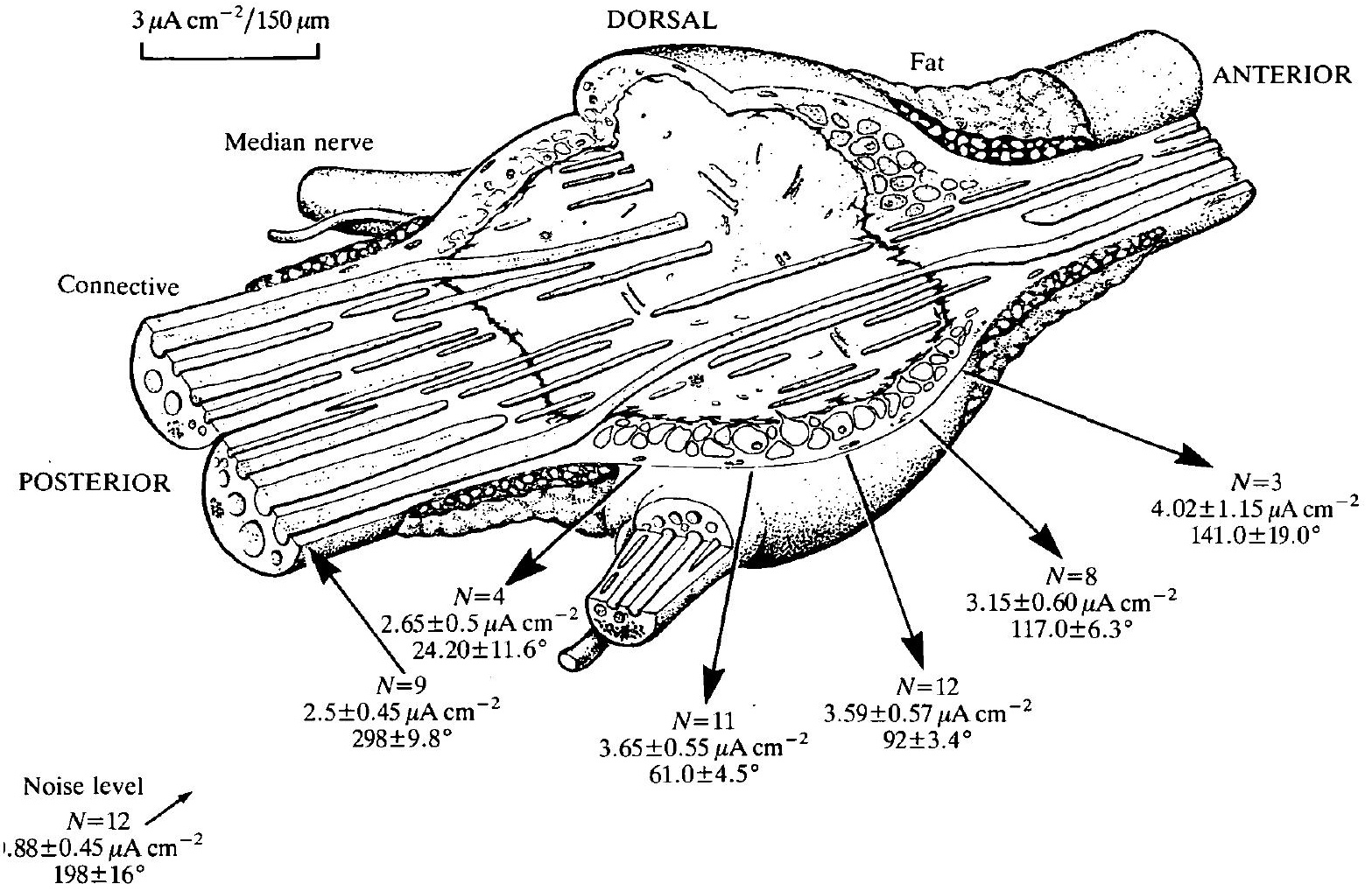

Fig. 1. Semi-diagrammatic illustration of the current flow from the equatorial plane of the fourth abdominal ganglion and the initial section of the penultimate connective in Periplaneta americana. Angles are plotted relative to the longitudinal midline of the nerve cord such that a vector with an angle of $180^{\circ}$ would point anteriorly and one with an angle of $0^{\circ}$ would point posteriorly. Standard errors about values of amplitude and angle are given as means \pm s.E. The background variation in the mean peak-to-peak noise level measured during the experiment is shown in the bottom left-hand corner.

\section{Current flow from a peripheral nerve}

In two preparations an inward current of $2.68 \pm 0.13 \mu \mathrm{A} \mathrm{cm}^{-2}$ ( \pm s.E., Table 1) was measured from the median nerve $200 \mu \mathrm{m}$ distal to its insertion into the fourth abdominal ganglion. The perineurial cells in this region were more like those seen in the connective than their ganglionic equivalents.

\section{Patterns of current flow in junctional regions}

The difference in the polarity of current flow between the ganglion and the connective or the peripheral nerve inevitably meant that at some point a reversal took place. Fig. 5 shows this in the case of the median nerve. Here the vector direction reversed rapidly as the probe advanced distally across the base of the herve. This pattern was consistent between preparations $(N=7)$, although inconsistencies in the probe and nerve positions made pooling the data impossible. 


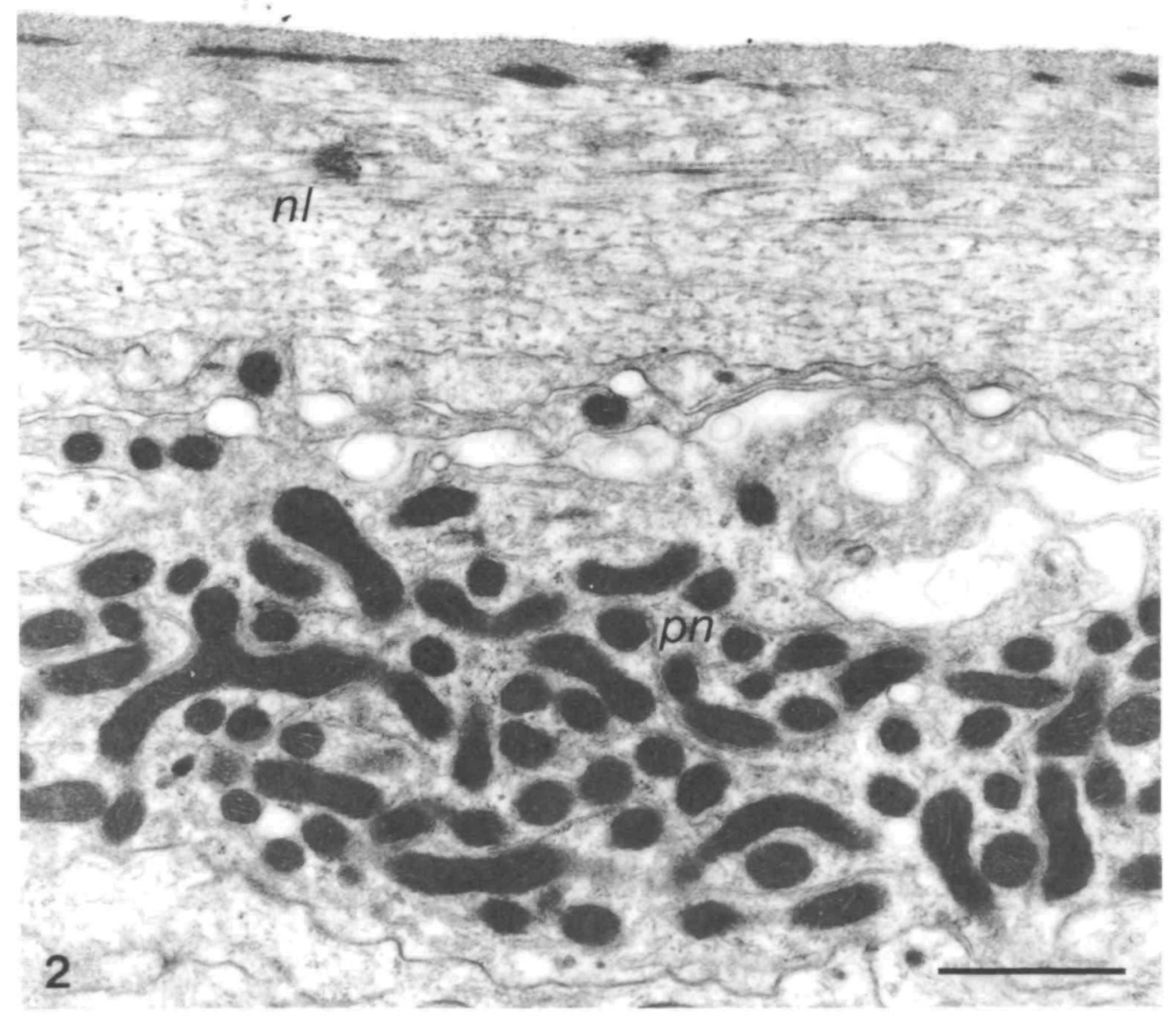

Fig. 2. Structure of the perineurial cells beneath the probe positions in the equatorial plane of the fourth abdominal ganglion. Note the large number of mitochondria in these cells. $n l$, neural lamella; $p n$, perineurial cell. Scale bar, $1 \mu \mathrm{m}$.

This zone of transition corresponded to a collar of cells containing large numbers of microtubules. Such cells were not seen in the ganglionic region, but they extended some distance along the median nerve.

As with the peripheral nerve a similar transitional region should exist between the connectives and the ganglion. Vector polarities indicated that this region lay close to the body of the ganglion but was obscured by fat tissue forming a blanket round the connectives in this area. This fat tissue was in close apposition to the neural lamella, preventing access of the probe to the surface of the connective (Fig. 6). The barrier cells lying between the connectives and the ganglionic perineurium were characteristically electron dense (Fig. 7), a feature caused by the high density of variously orientated microtubules (Fig. 8). These appeared to be restricted to the outer area of the cells and were reduced in number as cel. processes worked their way in amongst the axons and subperineurial glia (Fig. 7). 


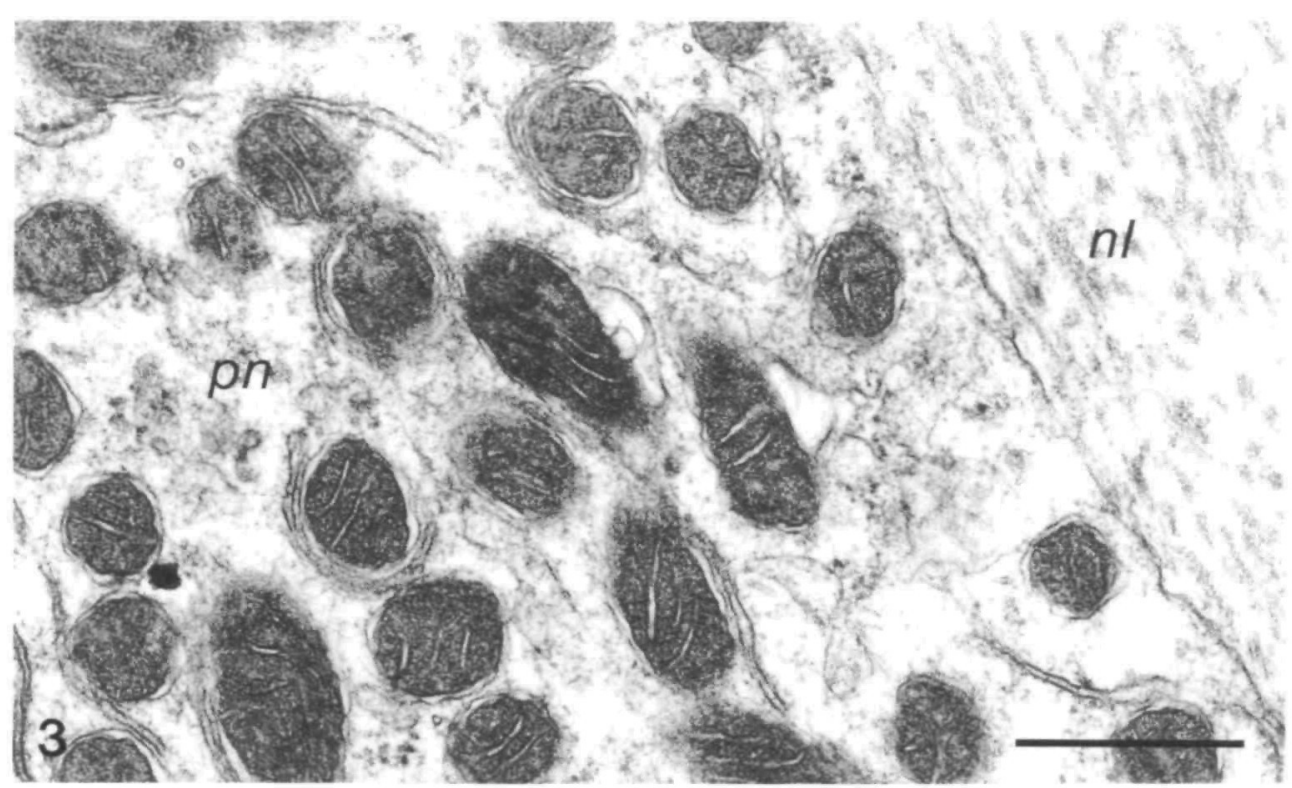

Fig. 3. Higher magnification of the cells from the ganglionic position shown in Fig. 2. Note here the close association of the mitochondria with membrane structures. $n l$, neural lamella; $p n$, perineurial cell. Scale bar, $0.5 \mu \mathrm{m}$.

Table 2. Current amplitudes and angles of flow from the central region of the penultimate connective

\begin{tabular}{lrcc}
\hline Preparation & $\begin{array}{c}\text { Number of } \\
\text { readings }\end{array}$ & $\begin{array}{c}\text { Amplitude } \\
\left(\mu \mathrm{A} \mathrm{cm} \text { ch }^{-2} \pm \text { s.D. }\right)\end{array}$ & $\begin{array}{c}\text { Angle } \\
\text { (degrees } \pm \text { s.D. })\end{array}$ \\
No. 1 & 12 & $1.01 \pm 0.18$ & $\begin{array}{c}\text { Inwards } \\
\text { Noise level }\end{array}$ \\
No. 2 & 5 & $0.58 \pm 0.31$ & $182.42 \pm 23.43$ \\
Noise level & 9 & $0.58 \pm 0.18$ & $64.20 \pm 26.70$ \\
& & $0.38 \pm 0.21$ & $197.00 \pm 124.20$ \\
Two preparations were examined and the variation in the peak-to-peak noise level during \\
measurement is also shown. \\
Measurements were made over a distance of approximately $400 \mu \mathrm{m}$.
\end{tabular}

This type of cell was seen on the anterior and posterior sides of the ganglion at the junction with the connectives.

\section{Discussion}

This study shows that there are distinct regional differences in the pattern of current flow from the insect abdominal nervous system. There is a net outward 


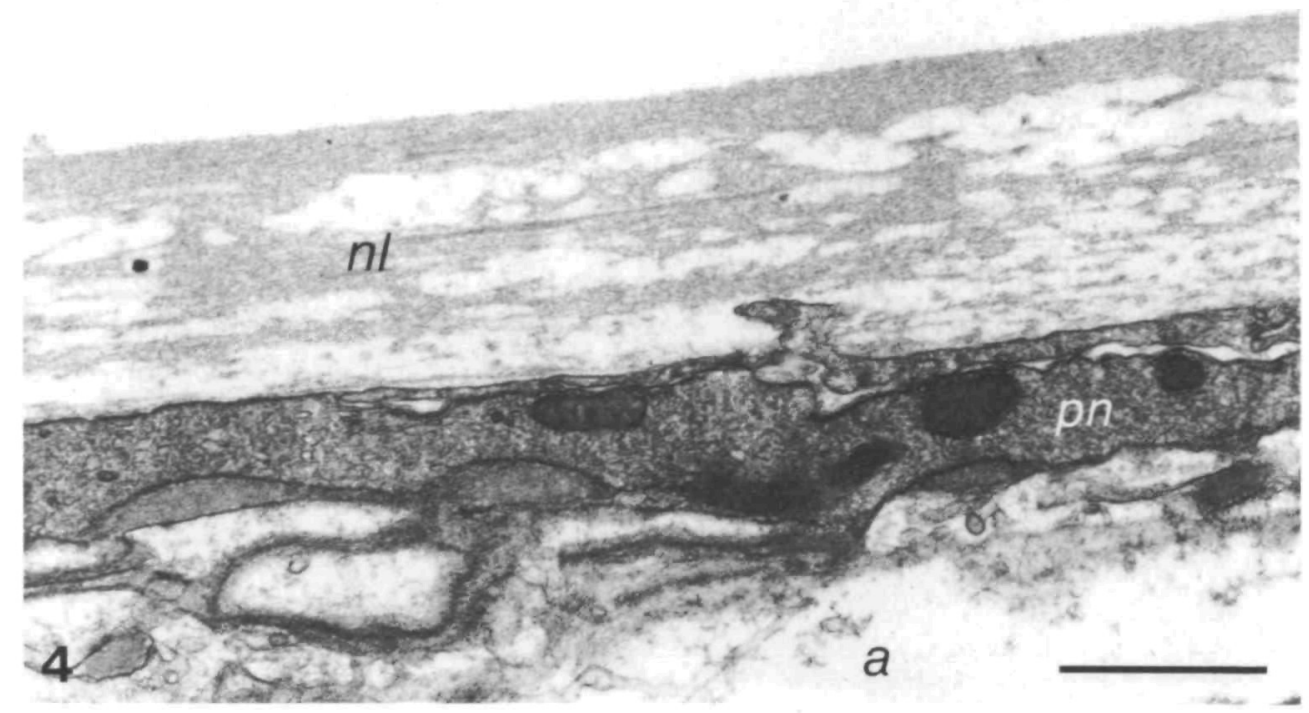

Fig. 4. Structure of the perineurial cells beneath the connective probe positions. This micrograph was taken from the region immediately adjacent to the ganglionic fat tissue. The structure appeared to be relatively uniform throughout the length of the connective. Note the attenuated nature of these cells in comparison with those in Fig. 2. $a$, axon; $n l$, neural lamella; $p n$, perineurial glial cell. Scale bar, $1 \mu \mathrm{m}$.

flow from the equatorial plane of the ganglion and a net inward current over the surface of the connective next to the ganglion. Ganglionic currents from the area measured are consistent, having a mean value of $3.16 \mu \mathrm{Acm}^{-2}$. They arise perpendicular to the surface. The pattern of current flow along the connective is more variable. The largest and most consistent current flows into the connective at the junction with the abdominal ganglion, where the mean amplitude is $2.11 \mu \mathrm{A} \mathrm{cm}^{-2}$, perpendicular to the surface. The polarity is opposite to that of the ganglion. A similar situation appears to exist for the median nerves. Away from this transitional region, along the equatorial plane of the connective, the currents are less regular in both amplitude and angle. Over a length of $500 \mu \mathrm{m}$ in the central region of the connective the mean inward current amplitude is $0.82 \pm 0.25 \mu \mathrm{A} \mathrm{cm}^{-2}$ $( \pm$ S.E.). This cannot be considered significantly greater than the peak-to-peak variation in the noise level.

The differences in the pattern of current flow from the abdominal ganglion and the penultimate connective suggest physiological differences in the barrier. Anatomical work on the abdominal ganglia and connectives of $P$. americana has already shown structural differences between these two regions of the CNS (Hess 1958; Maddrell and Treherne, 1967). The present study shows that the cell typd lying beneath the neural lamella in the equatorial plane of the ganglion is 


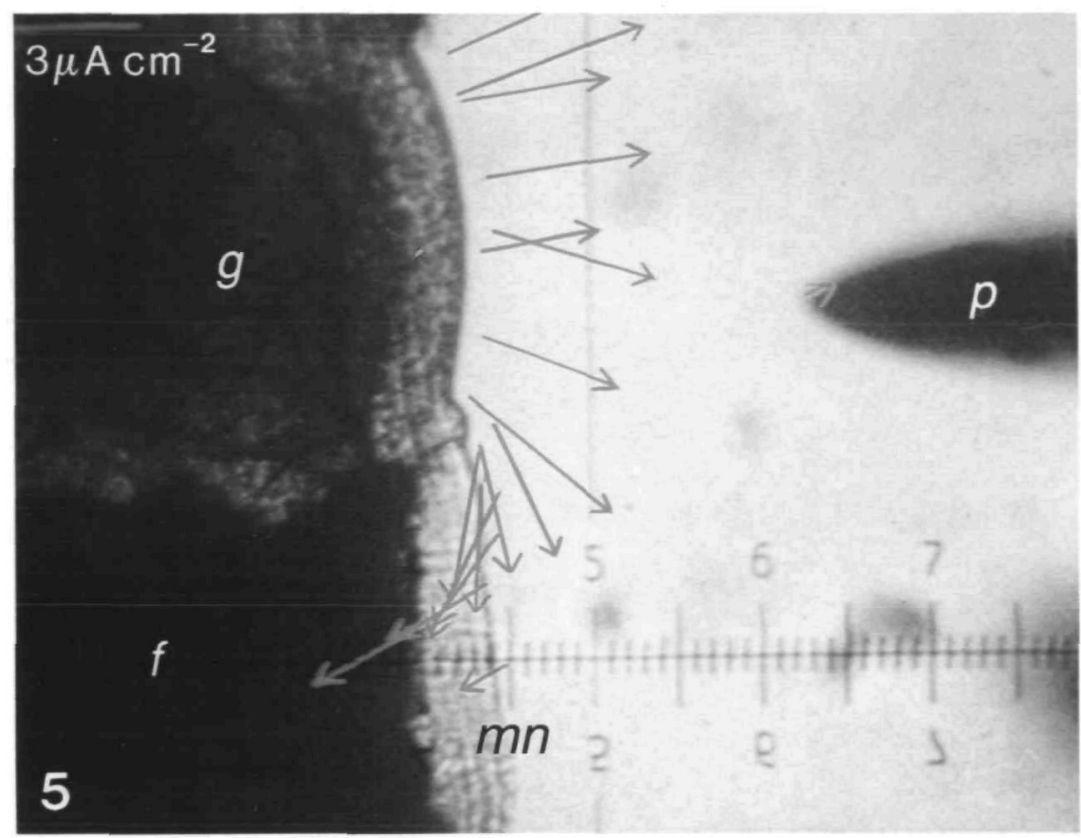

Fig. 5. A single experimental record of current flow from the equatorial plane of the fourth abdominal ganglion and median nerve. The median nerve is clearly visible against the contrasting fat tissue surrounding the posterior area of the ganglion and initial region of the penultimate connective. The current vectors were superimposed by computer on a video image. Current reverses between the ganglion and the peripheral nerve. The probe is shown offset in the reference position. $f$, fat body overlying the penultimate connective; $g$, fourth ganglion; $m n$, median nerve; $p$, probe. The small graticule divisions visible in the photograph equal $15 \mu \mathrm{m}$. 



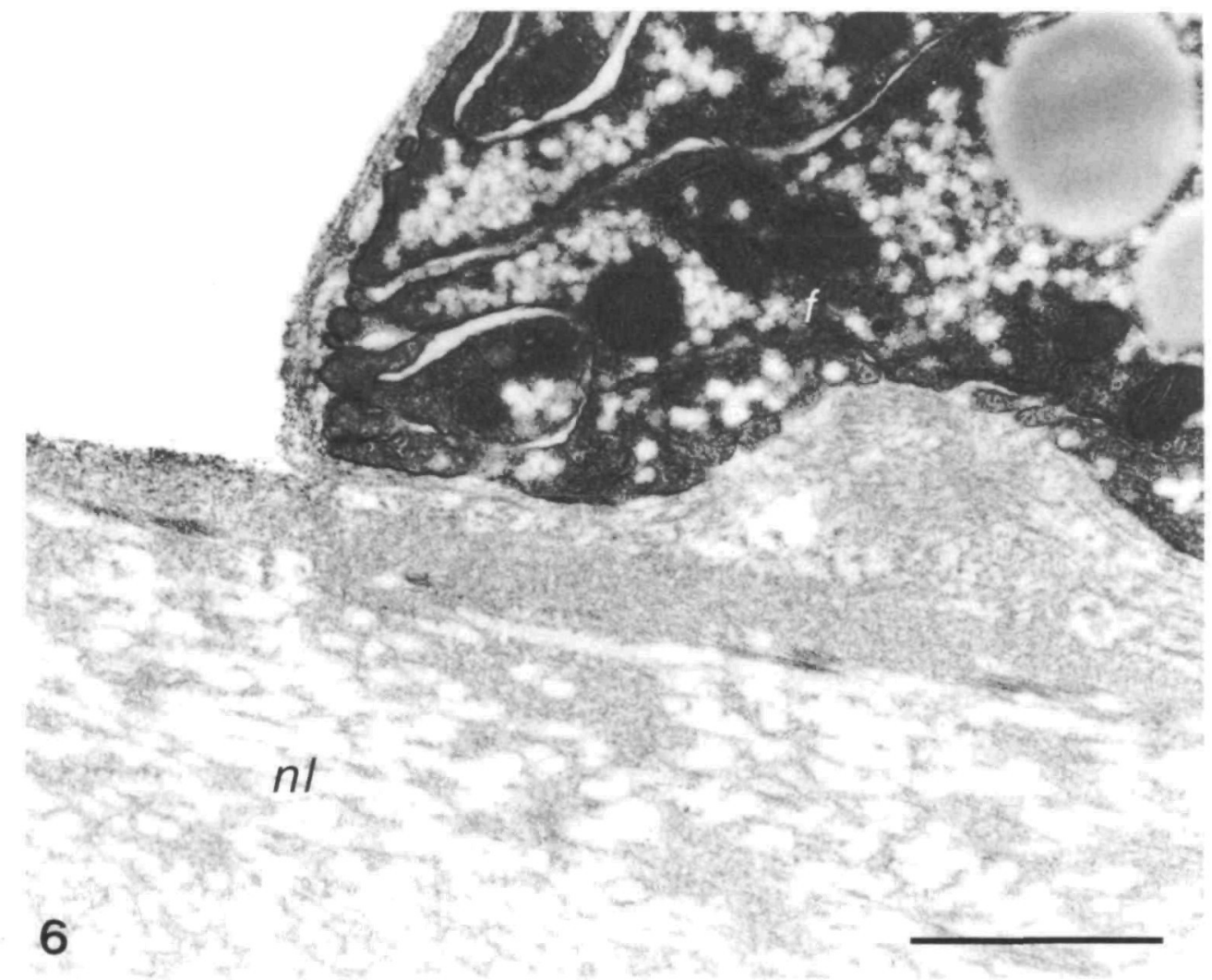

Fig. 6. Electron micrograph showing the close apposition between fat cells and the neural lamella adjacent to the fourth abdominal ganglion. $f$, fat cells; $n l$, neural lamella. Scale bar, $1 \mu \mathrm{m}$.

characterised by a high density of mitochondria, indicating a high level of metabolic activity. These organelles are closely associated with membrane structures of an indeterminate nature. Two possibilities exist: they are either smooth endoplasmic reticulum or basolateral infoldings of the glial membrane. A fixative specific for membrane structures will be needed to resolve these alternatives. Beneath these cells lie further glial layers, considerably folded, and with far fewer mitochondria. There are no detailed descriptions of the abdominal ganglia or the location of the ganglionic blood-brain barrier but, by analogy with the connective perineurium (Treherne, 1985), a high-resistance barrier with tight junctions occluding intercellular clefts would be expected in the region of the mitochondria-rich cells. The location of a superficial barrier is confirmed, in part, by the observation that the sheath potential generated across the ganglionic blood-brain barrier (Pichon and Boistel, 1967) can be found immediately below the perineurial cell layer (Schofield, 1990). However, the presence of large numbers of mitochondria sets these cells apart from those found in the same relative position of the connective, where the more attenuated and thinner cells of 


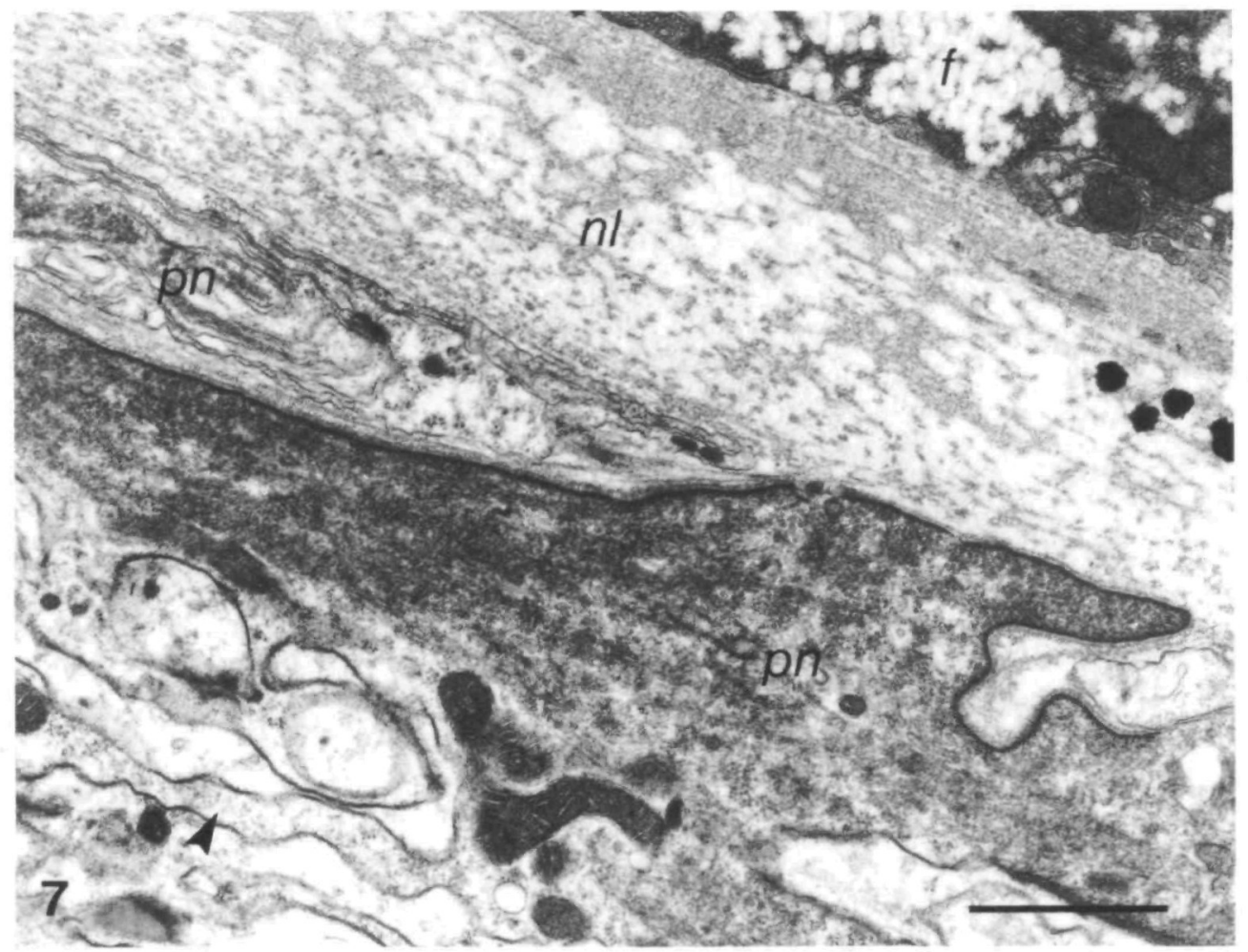

Fig. 7. Electron micrograph of the perineurial cells beneath the fat body at the boundary of the ganglion and the connective. Note the appearance of cells with a high density of microtubules. This feature is lost as these cells extend processes into the depth of the cord (arrowhead). $f$, fat cells; $n l$, neural lamella; $p n$, perineurial cells. Scale bar, $1 \mu \mathrm{m}$.

the connective barrier, with their sparse mitochondrial content, bear a greater morphological resemblance to those in the peripheral nerve.

The transitional regions between the connective, the ganglion and the peripheral nerves are marked by the appearance of a characteristic type of glial cell. These cells, rich in packed arrays of microtubules, mark a boundary where the outwardly directed ganglionic currents turn inwards. The function of this cell type is not known, but it could be structural. Such a role has already been suggested for similar cells in the peripheral nervous system (Blanco, 1988). The presence of the microtubules, however, also links these cells with those of the connective barrier, where microtubules can be present (Fig. 4), though seldom reaching the same density as in the transitional areas.

One of the largest steady extracellular currents measured by the vibrating probe technique comes from teleost opercular membrane. In this tissue a peak current density of $600 \mu \mathrm{A} \mathrm{cm}^{-2}$ has been localised over the apical crypt of two chloride cells (Scheffey et al. 1983). These cells possess large numbers of mitochondria 


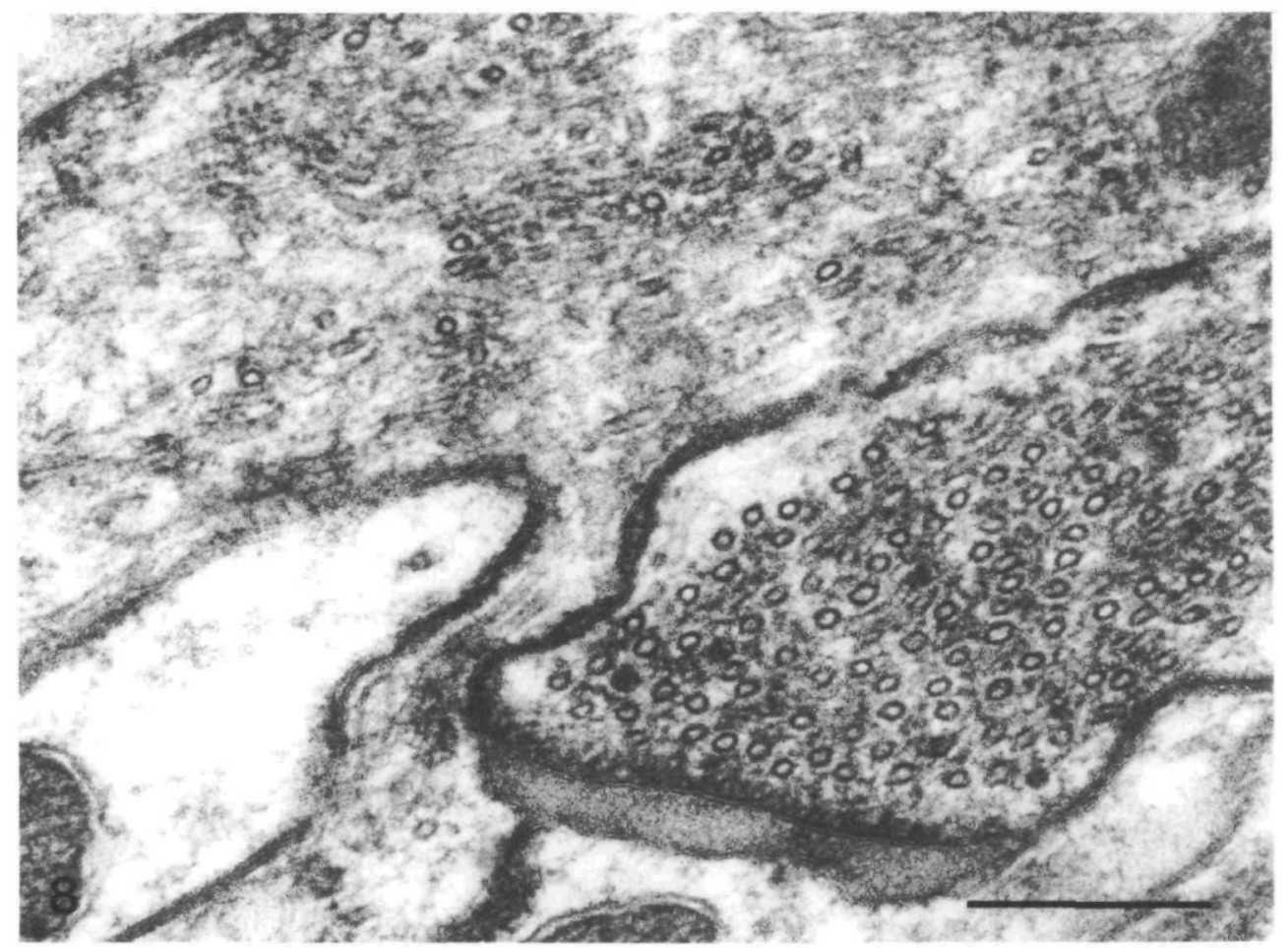

Fig. 8. Higher power photomicrograph of the cell type illustrated in Fig. 7, but from a different preparation, showing the high density of microtubules arranged in several orientations. Scale bar, $0.25 \mu \mathrm{m}$.

(Foskett et al. 1981) that presumably fuel, directly or indirectly, the large ionic fluxes observed. The net current is carried by chloride. The mitochondrial concentration in the chloride cell provides an obvious similarity with the perineurial cells of the ganglionic barrier. However, on the basis of other studies (Treherne and Schofield, 1981) it seems most feasible that the dominant current observed is carried by potassium ions.

The pattern of current flow observed in this study could be interpreted as follows. The movement of charged ions across the ganglionic barrier produces a net outward current as a result of active transport by the superficial ganglionic glia. This movement may be due to the mechanism behind ionic homeostasis, but could also reflect the involvement of ion transport in the uptake of nutrients. Such an interpretation would explain the high density of mitochondria in the outer cells and raises the possibility that the membrane structures closely associated with these organelles are basolateral infoldings of the glial membrane. Infoldings would greatly increase both the surface area of the ganglion and the proximity of ATP generation to the pumps. Current would leak back into the system via the connectives and nerves, seeking the most immediate route, and would thus be greater at the junctions with the ganglia. An alternative possibility is that the pump 
driving the currents may lie deeper in the system and the ion movements across both ganglionic and perineurial barriers would then be leakage currents driven passively by the electrochemical gradient. Further experiments are planned to shed some light on the identities of the ionic species involved and the location and characteristics of the pumps.

This work was funded from several sources, including the Royal Society, London, Sidney Sussex College, Cambridge, and the NIH. The authors would like to thank both Dr L. Jaffe and the late J. E. Treherne for their advice and encouragement and Drs P. K. Schofield, C. Scheffey and B. Gupta for helpful discussions.

\section{References}

Abbott, N. J. And Treherne, J. E. (1977). Homeostasis of the brain microenvironment: a comparative account. In Transport of Ions and Water in Animals (ed. B. L. Gupta, R. B. Moreton, J. L. Oschman and B. J. Wall), pp. 481-510. London, New York: Academic Press.

BlanCo, R. E. (1988). Glial cells in peripheral nerves of the cockroach, Periplaneta americana. Tissue and Cell 20, 771-782.

Fosketr, J. K., Logsdon, D., Turner, T., Machen, T. E. and Bern, H. A. (1981). Differentiation of the chloride extrusion mechanisms during seawater adaption of a teleost fish, the cichlid Sarotherodon mossambicus. J. exp. Biol. 93, 209-224.

Hess, H. (1958). The fine structure of nerve cells and fibres, neuroglia, and sheaths of the ganglion chain in the cockroach (Periplaneta americana). J. biophys. biochem. Cytol. 4, 731-741.

JAFFE, L. F. (1985). Extracellular current measurements with a vibrating probe. Trends Neurosci. 8, 517-521.

JAFFE, L. F. AND NuCCITELLI, R. (1974). An ultrasensitive vibrating probe for measuring steady extracellular currents. J. Cell Biol. 63, 614-628.

Maddrell, S. H. P. And Treherne, J. E. (1967). The ultrastructure of the perineurium in two insect species, Carausius morosus and Periplaneta americana. J. Cell Sci. 2, 119-128.

Pichon, Y. And Boistel, J. (1967). Microelectrode study of the resting and action potentials of the cockroach giant axon with special reference to the role played by the nerve sheath. $J$. exp. Biol. 47, 357-373.

SCHEFFEY, C. (1988). Two approaches to construction of vibrating probes for electrical current measurement in solution. Rev. Sci. Instrum. 59, 787-792.

Scheffey, C., Foskett, J. K. AND MACHEN, T. E. (1983). Localization of ionic pathways in the teleost opercular membrane by extracellular recording with a vibrating probe. J. Membr. Biol. 75, 193-203.

Schofield, P. K. (1990). Oscillations of glial membrane potential in a localized region of the blood-brain barrier of an insect. J. exp. Biol. 148, 335-351.

Trenerne, J. E. (1985). Blood-brain barrier. In Comprehensive Insect Physiology, Biochemistry and Pharmacology, vol. 5 (ed. G. A. Kerkut and L. I. Gilbert), pp. 115-137. Oxford: Pergamon Press.

Treherne, J. E. AND SChofield, P. K. (1981). Mechanisms of ionic homeostasis in the central nervous system of an insect (Periplaneta americana). J. exp. Biol. 95, 61-74.

Weevers, R. DE G. (1985). The insect ganglia. In Comprehensive Insect Physiology, Biochemistry and Pharmacology, vol. 5 (ed. G. A. Kerkut and L. I. Gilbert), pp. 213-297. Oxford: Pergamon Press. 